\title{
Communication \\ Multi-Disciplinary Care Planning of Ovarian Cancer in Older Patients: General Statement-A Position Paper from SOFOG-GINECO-FRANCOGYN-SFPO
}

\author{
Leila Bengrine $^{1}$, Naoual Bakrin ${ }^{2}(\mathbb{D})$, Frédérique Rousseau ${ }^{3}$, Vincent Lavoué ${ }^{4,5}$ (D) and Claire Falandry ${ }^{6,7,8, *(D)}$
}

1 SOFOG, GINECO, Medical Oncology Department, Centre Georges-Francois Leclerc, 21000 Dijon, France; lbengrine@cgfl.fr

2 GINECO, Hospices Civils de Lyon, Digestive Surgery Department, Hôpital Lyon-Sud, CEDEX, 69495 Pierre-Bénite, France; naoual.bakrin@chu-lyon.fr

3 SOFOG, GINECO, Paoli Calmettes Institute, 13009 Marseille, France; rousseauf@ipc.unicancer.fr

4 FRANCOGYN, Gynecology Department, CHU de Rennes, Hôpital Sud, 35000 Rennes, France; vincent.lavoue@chu-rennes.fr

5 UMR S1085, IRSET-INSERM, Rennes University, 35000 Rennes, France

6 SOFOG, GINECO, Hospices Civils de Lyon, Geriatrics Department, Hôpital Lyon Sud, 69230 Saint Genis-Laval, France

7 CarMeN Laboratory, INSERM U.1060, Université Lyon1, INRA U. 1397, INSA Lyon, Hospices Civils Lyon, Bâtiment CENS-ELI 2D, Hôpital Lyon Sud Secteur 2, 69310 Pierre Bénite, France

8 UCOGIR-Auvergne-Rhône-Alpes Ouest-Guyane, Charles Mérieux Medical School, ONCOAGE FHU, 69310 Pierre Bénite, France

* Correspondence: claire.falandry@chu-lyon.fr

check for

updates

Citation: Bengrine, L.; Bakrin, N.;

Rousseau, F.; Lavoué, V.; Falandry, C. Multi-Disciplinary Care Planning of Ovarian Cancer in Older Patients: General Statement-A Position Paper from SOFOG-GINECOFRANCOGYN-SFPO. Cancers 2022, 14, 1295. https://doi.org/10.3390/ cancers14051295

Academic Editor: Andrea Ciavattini

Received: 28 December 2021

Accepted: 25 February 2022

Published: 2 March 2022

Publisher's Note: MDPI stays neutral with regard to jurisdictional claims in published maps and institutional affiliations.

Copyright: () 2022 by the authors Licensee MDPI, Basel, Switzerland. This article is an open access article distributed under the terms and conditions of the Creative Commons Attribution (CC BY) license (https:// creativecommons.org/licenses/by/ $4.0 /)$.
Simple Summary: This position paper aims to provide practitioners a proposal for multidisciplinary care planning for older patients with ovarian cancer from the time of suspected diagnosis. The firstline treatment of advanced ovarian cancer involves several interdependent sequences: cytoreductive surgery, (neo)adjuvant chemotherapy and maintenance targeted treatments. In older patients, care planning must be adapted to their geriatric parameters and consider the geriatric impact of each treatment sequence to allow treatment completion. Care planning should be centered on patient motivation and imply multidisciplinarity. Each step of treatment plan should be reconsidered in light of a geriatric assessment and follow-up. Studies are needed to prospectively evaluate the impact of geriatric vulnerability parameters at each step of the treatment agenda and the impact of geriatric interventions on patient outcomes.

\begin{abstract}
In this position paper the Société Francophone d'OncoGériatrie (SOFOG; French-speaking oncogeriatric society), the Société Française de Pharmacie Oncologique (SFPO, French society for oncology pharmacy), the Groupe d'Investigateurs Nationaux pour l'Étude des Cancers de l'Ovaire et du sein (GINECO, National Investigators' Group for Studies in Ovarian and Breast Cancer) and the Groupe Français de chirurgie Oncologique et Gynécologique (FRANCOGYN) propose a multidisciplinary care planning of ovarian cancer in older patients. The treatment pathway is based on four successive decisional nodes (diagnosis, resectability assessment, operability assessment, adjuvant, and maintenance treatment decision) implying multidisciplinarity and adaptation of the treatment plan according to the patient's geriatric covariates and her motivation towards treatment. Specific attention must be paid to geriatric intervention, supportive care and pharmaceutical conciliation. Studies are needed to prospectively evaluate the impact of geriatric vulnerability parameters at each step of the treatment agenda and the impact of geriatric interventions on patient outcomes.
\end{abstract}

Keywords: ovarian cancer; older patient; oncogeriatrics; geriatric assessment; vulnerability; care plan; strategy 


\section{Introduction}

Management of advanced ovarian cancer has been progressively standardized over recent decades to the association of an extensive cytoreductive surgery and adjuvant chemotherapy; this allowed overall survival rates to improve, and the median survival now exceeds 40 months [1]. Cancer control is also further prolonged in patients receiving bevacizumab and Poly (ADP-ribose) polymerase inhibitors (PARPi) as maintenance therapies [2]. Nevertheless, the reported overall survival of older patients, in population-based studies and even in randomized trials, remains poor due to the presence of comorbidities, polypharmacy and frailty in this population, as these factors impede optimal management [3-6]. This may be explained by a priori concerns; for example, age is frequently associated with poorer application of recommendations [3] but also a posteriori such as excessive toxicities, leading to dose limitations, treatment discontinuation and even debates about the treatment paradigms in the oldest old [7]. However, optimal management is defined according to data collected in younger populations since older patients are seldomly included in pivotal trials [8] and when included represent a highly selective population, differing from "true" older patients [9-11]. Data for the treatment of older patients are derived from retrospective studies of selected populations [12], subgroup analyses of pivotal randomized trials [13,14], real-life unselected population-based studies [5] and specific clinical trials conducted in older patients, but these seldomly integrate assessment of geriatric covariates. These are often small and non-comparative phase II studies, and there is heterogeneity in the geriatric covariates explored. In this context, results are often not comparable, and guidelines may be difficult to elaborate. Nevertheless, this question stays of major interest, since the median age of ovarian cancer at diagnosis reached 68 years in France in 2019 [15].

The international community has identified geriatric oncology as a priority for many tumors, and the Gynecological Cancer InterGroup (GCIG) identified during its fourth consensus conference the need to develop research involving older patients with the following objectives: (i) reduce selection bias in pivotal trials; (ii) assess better and prospectively, using stratification methods, geriatric covariates in such trials and (iii) conduct specific trials devoted to older patients that may not be included in randomized studies due to different characteristics or poorer prognosis [16]. More recently the French national cancer institute (Institut national du cancer, INCa) coordinated national recommendations on ovarian cancer and dedicated a specific chapter to older patients [17]. In parallel, the geriatric oncology community aims to share the objectives of geriatricians that are to avoid under-treatment, over-treatment and bad practices; an additional challenge is to provide older patients with access to therapeutic innovation.

This position paper aims, in this context of a relatively low level of evidence, to provide practitioners a proposal for multidisciplinary care planning for older patients with ovarian cancer from the time of suspected diagnosis. It summarizes the proposals of a working group composed of members of two learned societies and two investigator groups: the Société Francophone d'OncoGériatrie (SOFOG; French-speaking oncogeriatric society), the Société Française de Pharmacie Oncologique (SFPO, French society for oncology pharmacy), the Groupe d'Investigateurs Nationaux pour l'Étude des Cancers de l'Ovaire et du sein (GINECO, National Investigators' Group for Studies in Ovarian and Breast Cancer), and the Groupe Français de chirurgie Oncologique et Gynécologique (FRANCOGYN, French research group for oncologic gynecologic surgery). The patient's care course is hereafter conceptualized as the succession of several decisional nodes in which the classical risk/benefit ratio is enriched by the adjunct of geriatric assessment and, when data are available, the way such geriatric assessment may modify patients' treatment schedule.

\section{General Considerations for Anticipating the Treatment Care Planning Agenda}

Ovarian cancer in older patients is frequently perceived as a dramatic change in the physiological trajectory of the patient, a perfect illustration of frailty and the so-called "geriatric cascade" or "domino effect" [18]. Due to cancer-related covariables (for example, frequent diagnosis at a later stage of tumors that are histologically more aggressive $[19,20]$ ) 
or to patient-related covariables, older patients suffering from ovarian cancer present frequently at diagnosis a rapid functional, nutritional and psychological deconditioning [21]. The challenges of cancer treatment therefore reside in a personalized, anticipated and adaptive treatment plan that should integrate two opposing constraints: Provide to each patient the best specific oncological treatment based on evidence-based medicine without precipitation of geriatric deconditioning or functional loss. Other points to consider are, at each decision step, the opinion of the patient and her family on cancer treatment, their motivation towards specific treatment and geriatric rehabilitation, as well as the shared objectives of the treatment plan, with a particular attention paid to quality of life and functional preservation more than quantity of life, and supportive care [22].

What Are the General Principles of Such Treatment Care Planning?

Some concepts may be highlighted to provide a general framework for the principles of care.

First, complete surgery provides the same overall survival benefit to older patients as it does to their younger counterparts [23]. However, due to a higher risk of perioperative morbidity and mortality [5] this benefit becomes clear 16 months after surgery; moreover, surgery is less frequently complete in older patients [3]. In addition, surgery induces not only a high risk of perioperative morbidity and mortality but also geriatric deconditioning [24] and impairs the dose intensity of subsequent chemotherapy [7,25]. Consequently, decisions on surgery should be made as often as possible based on preliminary laparoscopic assessment, and starting cytoreductive surgery that may not be completed should be discouraged [26].

Second, some categories of patients do not benefit from upfront surgery, namely patients older than 75 years of age with stage IV ovarian cancer or with stage III ovarian cancer and evolving comorbidity [27]. For these patients, upfront chemotherapy offers a greater incremental cost-effectiveness ratio (ICER) [28]. In addition, patients with a geriatric vulnerability score (GVS) $\geq 3$ (i.e., three or more impaired geriatric parameters among the following: altered activities of daily living (ADL) or instrumental ADL (IADL), hypoalbuminemia, altered hospital anxiety and depression scale (HADS) or lymphopenia) are a significant risk of premature death [21] and should probably not be offered upfront surgery.

Third, when upfront surgery is performed, the risk is high that adjuvant chemotherapy is delivered later [25], using monotherapy [7], and with a reduced dose intensity [25].

Fourth, neoadjuvant chemotherapy provides an opportunity to decrease the complexity of cytoreductive surgery and perioperative complications [29], implement a geriatric plan that will address specifically the geriatric covariates identified during the initial geriatric assessment and optimize patients' status before surgery (when interval surgery is expected to be proposed).

Based on these broad outlines, each treatment decision should consider tumor-specific and patient-specific characteristics to coordinate an individualized treatment plan coordinating the different "blocks" of treatment that are developed below in the following order: diagnosis, chemotherapy, surgery, adjuvant and maintenance treatments including targeted therapies (Figure 1). Considering the lack of data available to distinguish different outcomes of older patients receiving chemotherapy with neoadjuvant, adjuvant or palliative (without any surgical plan) intent, all data are gathered under the section entitled chemotherapy.

In addition, and as a first step to enter such an individualized care plan, the benefit of performing a geriatric assessment from the time of diagnosis and of implementing a geriatric care plan coordinated with the oncological plan is presented. 
Pelvic mass

+/- ascites

Node 1:

Confirmation and extension diagnosis

Node 2:

Resectable?

(see figure 2)

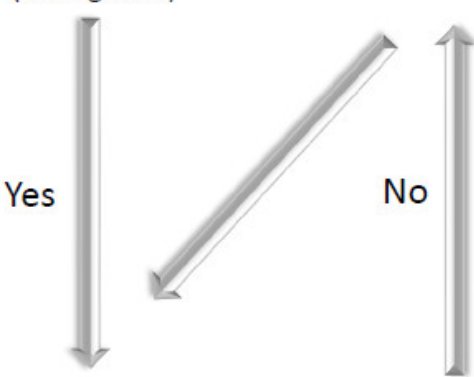

Node 3:

Operable?

(see figure 2)

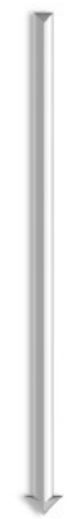

Node 4:

Adjuvant and maintenance treatments

\section{Assessment at diagnosis}

\begin{tabular}{|c|c|c|c|}
\hline & Paraclinical & Histological & Geriatric \\
\hline 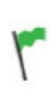 & $\begin{array}{l}\text {-Pelvic MRI } \\
\text {-CT scanner } \\
\text {-Laparoscopy } \\
\text { - CA125 }\end{array}$ & $\begin{array}{l}\text { - Laparoscopic assessment (correct } \\
\text { size, for histology and molecular } \\
\text { analysis: HRD, BRCA) }\end{array}$ & $\begin{array}{l}\text {-Si } G 8>14 \text {, geriatric assessment to } \\
\text { discuss }\end{array}$ \\
\hline$F^{\prime \prime}$ & $\begin{array}{l}\text { - No injected CT scan if } \\
\text { creatinine clearance }<40 \\
\mathrm{ml} / \mathrm{mn} \\
\text { - No gadolinium if creatinine } \\
\text { clearance }<30 \mathrm{ml} / \mathrm{mn} \\
\text { - No } \mathrm{MRI} \text { if pace maker }\end{array}$ & $\begin{array}{l}\text { - If laparoscopic assessment contra- } \\
\text { indicated: } \\
\text { * Cytologic sample if CA125/CEA ratio } \\
>25 \\
\text { * Radiological biopsy of carcinoma } \\
\text { nodule(s) - anticipate sufficient } \\
\text { sampling }\end{array}$ & $\begin{array}{l}\text { Warning if more than } 3 \text { domains of } \\
\text { GVS impaired GVS (ADL, IADL, } \\
\text { HADS, albuminemia, , lymphocytes) } \\
\text { => high toxicity risk } \\
\text { => consider primary chemotherapy }\end{array}$ \\
\hline
\end{tabular}

\section{+/- primary chemotherapy}

\begin{tabular}{|c|c|c|}
\hline & Chimiotherapy & Supportive/geriatric care \\
\hline 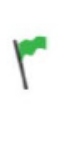 & $\begin{array}{l}\text {-Standard 3-weekly carboplatin(c) paclitaxel (p) (c: } \\
\text { AUC } 5 \text { p: } 175 \mathrm{mg} / \mathrm{m}^{2} \text { ) } \\
\text { - Weekly carboplatin paclitaxel (MITO 7) (c: AUC2; } \\
\text { p:60mg/ } / \mathrm{m}^{2} \text { ) }\end{array}$ & $\begin{array}{l}\text {-Pharmacist optimization with comprehensive } \\
\text { medication review } \\
\text {-Consider: } \\
\text {-G-CSF } \\
\text {-Nutritional support } \\
\text {-Nurse supervision }\end{array}$ \\
\hline$F$ & $\begin{array}{l}\text {-According EWOC-1 trial: carboplatin-paclitaxel } \\
\text { combination; no carboplatin monotherapy } \\
\text { - consider weekly carboplatin paclitaxel (MITO 7) (c: } \\
\text { AUC2; p:60mg/m²)? } \\
\text { - consider early reassessment } \\
\text { - Under discussion: dose escalation }\end{array}$ & $\begin{array}{l}\text { Idem supra + Personalized oncogeriatric care planning } \\
\text { according geriatric assessment with a special } \\
\text { watchfulness on: } \\
-\quad \text { Social isolation } \\
\text { - } \quad \text { Risk of falling } \\
\text { Depressive symptoms (reassessment, consider } \\
\text { antidepressant) }\end{array}$ \\
\hline
\end{tabular}

\section{Operability (for resectability see figure 2)}

\begin{tabular}{|c|c|c|}
\hline & Preoperative assessment & Postoperative \\
\hline 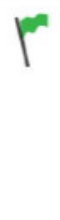 & 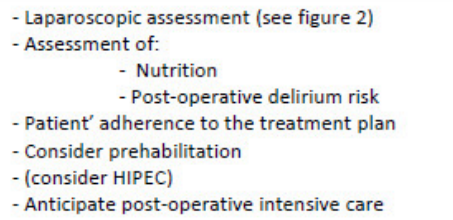 & \\
\hline${ }^{\prime \prime}$ & $\begin{array}{l}\text { Idem supra + special watchfulness on: } \\
\text { - Cognitive disorders } \\
\text { - Severe malnutrition: consider preoperative } \\
\text { artificial feeding } \\
\text { - Pharmaceutical optimization } \\
\text { - Adherence of the patient and her family to the } \\
\text { treatment plan +++ }\end{array}$ & $\begin{array}{l}\text { - Prevention of delirium (+/- presence of the } \\
\text { caregiver) } \\
\text { - Avoidance of confusiogenic drugsOptimal pain } \\
\text { management }\end{array}$ \\
\hline
\end{tabular}

Adjuvant and maintenance treatments

\begin{tabular}{|c|c|c|c|c|}
\hline & Chemotherapy & Bevacizumab & PARP inhibitors & Supportive/geriatric care \\
\hline F & $\begin{array}{l}\text {-Standard 3-weekly } \\
\text { carboplatin(c) paclitaxel } \\
\text { (p) (c: AUC } 5 \\
\left.\text { p: } 175 \mathrm{mg} / \mathrm{m}^{2}\right) \\
\text { - Weekly carboplatin } \\
\text { paclitaxel (MITO 7) (c: } \\
\text { AUC2; p:60mg/m²) }\end{array}$ & - 4 weeks after surgery & $\begin{array}{l}\text { BRCA somatic } \\
\text { mutation/HRD status: } \\
\text { olaparib } \\
\text { HRP status : niraparib } \\
\text { Pharmaceutical } \\
\text { optimization +++ }\end{array}$ & $\begin{array}{l}\text {-Pharmacist optimization } \\
\text { with comprehensive } \\
\text { medication review } \\
\text {-Consider: } \\
\text {-G-CSF } \\
\text {-Nutritional support } \\
\text {-Nurse supervision }\end{array}$ \\
\hline F & $\begin{array}{l}\text {-According EWOC-1 trial: } \\
\text { carboplatin-paclitaxel } \\
\text { combination; no } \\
\text { carboplatin } \\
\text { monotherapy } \\
\text { - consider weekly } \\
\text { carboplatin paclitaxel } \\
\text { (MITO 7) (c: AUC2; } \\
\text { p:60mg/m²)? }\end{array}$ & $\begin{array}{l}\text { - Recent cardiovascular } \\
\text { history } \\
\text { - Uncontrolled high } \\
\text { blood pressure }\end{array}$ & $\begin{array}{l}\text { - Idem supra } \\
\text {-Limits? Brakes? } \\
\text { Pharmaceutical } \\
\text { optimization +++ }\end{array}$ & $\begin{array}{l}\text { Idem supra } \\
\text { + Personalized } \\
\text { oncogeriatric care } \\
\text { planning according } \\
\text { geriatric assessment }\end{array}$ \\
\hline
\end{tabular}

Figure 1. Care planning in older patients with advanced ovarian cancer: steps to be considered from diagnosis to treatment in case of geriatric green (fit patient) or yellow (vulnerable patient) flags; ADL: activities of daily living; AUC: area under the curve; CA-125: carcinoma antigen 125; CEA: carcinoembryonic antigen; EWOC-1: elderly women with ovarian cancer trial 1; IADL: instrumental 
ADL; GVS: geriatric vulnerability score; HADS: Hospital Anxiety and Depression Scale; HRD: homologous recombination deficient; HRP: homologous recombination proficient; MITO-7: Multicenter Italian Trial in Ovarian Cancer study 7; ?: to be discussed; +++: important or even necessary.

\section{Diagnosis}

\subsection{Histological Diagnosis}

Epithelial ovarian cancer classically requires the association of a radiological pelvic mass and evocative histological sampling compatible with a gynecological origin [30]. Such sampling may come from a laparoscopic assessment, providing both a histological and extension diagnosis or, when the risk/benefit ratio is unsatisfactory for general anesthesia, from image-guided sampling. When histological sampling is considered high risk, an evocative cytology associated with a CA125/CEA ratio greater than 25 is accepted as an alternative [31]. However, image-guided techniques may not be able to provide sufficiently large tissue samples for treatment individualization. The risk is high that such non-invasive sampling methods are favored for older populations leading to a putative reduced access to therapeutic innovation (PARPi, clinical trial participation, etc.). Consequently, classical histological sampling should always be encouraged, and cytology considered as an exception (Figure 1, node 1).

\subsection{Operability and Resectability}

Upfront cytoreductive surgery followed by six courses of platinum-based chemotherapy is the standard treatment of patients with resectable stage III advanced ovarian cancer. However, the high proportion of advanced disease in older women and its general and geriatric consequences often prevent upfront surgery. In such cases neoadjuvant chemotherapy may be considered as an alternative treatment option [26,29]. The decision for neoadjuvant chemotherapy integrates both the resectability of the tumor and operability of the patient. Resectability refers to the ability of the surgeon to perform a complete cytoreduction (evaluated using the Essen or Leuven criteria [32]), whereas operability addresses the issue of whether a surgical plan is safe for an individual patient; the latter is based in particular on geriatric vulnerabilities. Thus, nutritional status, comorbidities and general condition assessment are needed to assess operability, as it has been shown that elevated Charlson comorbidity index and hypoalbuminemia are independent prognostic factors associated with severe complications after upfront surgery [33]. Some histological subtypes, such as mucinous, clear cell and low-grade serous carcinoma, have low response rates to chemotherapy; such patients should be proposed for maximal effort of complete surgical cytoreduction given the poor benefit of chemotherapy in these cases. In other cases, neoadjuvant chemotherapy must be considered when the tumor is not resectable and/or the patient is not operable; the latter must be reassessed after three courses of chemotherapy to propose interval surgery.

\section{Chemotherapy}

\subsection{Defining the Regimen with the Best Efficacy to Tolerability Profile}

Considering both the substantial extent of cancer at diagnosis and geriatric factors of vulnerability, primary chemotherapy is frequently considered as a reasonable therapeutic option, either with a neo-adjuvant or a palliative intent, when surgery is definitively rejected. Geriatric cofactors may also impact chemotherapy tolerance and challenge the predefined standards of treatment. From the beginning of the 1990s, the GINECO led several prospective studies of the Elderly Women with Ovarian cancer Trials (EWOT) program to define the geriatric covariates associated with treatment tolerance and patients' outcomes. A first study, EWOT-1, evaluated the treatment completion rate of a combination of cyclophosphamide and carboplatin; the prognostic factors for lower overall survival were depression, a high level of comedication and cancer stage; toxicity rates were higher when patients presented depression or instrumental ADL impairment [34]. This was 
followed by EWOT-2, which evaluated the treatment completion rate of the standard 3weekly paclitaxel $175 \mathrm{mg} / \mathrm{m}^{2}$ and carboplatin area under the curve (AUC) $5 \mathrm{mg} / \mathrm{mL} \cdot \mathrm{min}$ combination. Again, depression-according the investigator and evaluated using HADS, was a prognostic factor for overall survival [35]. When considering a pooled analysis of EWOT-1 and EWOT-2 results, factors associated with overall survival were depression, lymphopenia, stage IV cancer and the use of paclitaxel. The third study, EWOT-3, evaluated the treatment completion rate of a carboplatin monotherapy, with a special attention to depression assessment and to the impact of a standardized geriatric assessment on treatment completion and toxicity rates. The study led to the development of a geriatric vulnerability score (GVS) that includes five vulnerability covariates: ADL score $<6 / 6$; IADL score $<25 / 27$, albuminemia $<35 \mathrm{~g} / \mathrm{L}$, lymphopenia $<1 \mathrm{G} / \mathrm{L}$ and HADS score $>14 / 42$; patients are considered as vulnerable if they have at least three of these parameters (GVS $\geq 3$ ) [21]. These were followed by the Multicentre Italian Trial in Ovarian Cancer (MITO)-5 study that demonstrated that weekly administration of paclitaxel and carboplatin in older patients (paclitaxel $60 \mathrm{mg} / \mathrm{m}^{2}$ and carboplatin AUC $2 \mathrm{mg} / \mathrm{mL} \cdot \mathrm{min}$ on D1, D8 and D15 every 4 weeks) was feasible as it was associated with a low frequency of unacceptable toxicity $(11.5 \%)$ [36].

Based on the data from these four reports, the randomized phase II EWOC-1 study was designed to evaluate the treatment completion rates of a standard 3-weekly paclitaxel carboplatin regimen, a weekly paclitaxel carboplatin regimen as in the MITO-5 study and a carboplatin monotherapy in patients with a GVS $\geq 3$. Single-agent carboplatin was less active with significantly worse survival outcomes suggesting that even vulnerable patients should receive a combined treatment [37].

\subsection{Supportive Care Must Be Associated with Chemotherapy}

Chemotherapy needs to be associated with current standards of supportive care developed in the younger populations and completed with geriatric interventions proposed during the comprehensive geriatric assessment, especially nutritional care, fall prevention and management of social isolation [38].

Supportive care should prevent serious adverse events of chemotherapy. Hematologic toxicity will be prevented by prophylactic hematopoietic growth factors and digestive toxicity by systematic anti emetic treatment. Daily nursing supervision should be set up as soon as the patient is discharged from hospital. This supervision will allow close monitoring of chemotherapy's tolerance, blood pressure and temperature [39]. Pharmacists can also be implicated in this follow-up, notably in case of treatment delivery, to promote the patient's adherence and pharmaceutical conciliation.

\section{Surgery}

Curative surgery in ovarian carcinoma aims to achieve a complete clearance of the abdominal cavity [23]. The extent of residual disease is a strong prognostic factor [5,23], and in cases of low chemosensitivity maximal surgical effort can even restore prognosis [40]. However, this complex surgery includes digestive tract, urological and peritoneal procedures and is challenging in older women with comorbid conditions and high risk of post-operative complications [41,42]. Incomplete surgery is more frequent [43], partially due to surgeons modifying their cytoreductive approach, which seems to lead to decreased bowel resections [3]. Post-operative morbidity may delay the onset of adjuvant chemotherapy [44], decrease its dose intensity [7] and increase chemotherapy-related toxicity [25,45], leading some authors to question the treatment paradigm that includes surgery for the oldest patients [7].

Some studies have attempted to define predictive factors of excess morbidity in women undergoing cytoreduction. For instance, Wright et al. identified age, comorbidity and the number of procedures performed as the strongest predictors of medical complications that ranged from $10.2 \%$ in patients aged $<50$ years of age who underwent 0 radical procedures to $33.3 \%$ for patients aged $\geq 80$ years with $\geq 2$ procedures [46]. According to Gerestein et al. 
post-operative morbidity can be predicted by age, performance status, extent of surgery and operative time [47]. Taken together, age and surgical complexity appear as robust predictors of post-operative morbidity. It is also of note that Gerestein et al. had previously reported in a systematic analysis on post-operative mortality that the overall mean was $2.8 \%$ and that it was $3.7 \%$ for primary surgery [48], illustrating the decreased complexity and morbidity of interval compared to primary surgery [29]; the authors also highlighted the importance of the technical platform and the expertise of the surgical team [48], which may explain the wide range of mortality between studies notably in the oldest patients ( $\geq 80$ years) that ranged from $5.4 \%$ at 30 days for Diaz-Montes et al. [20] to $11.7 \%$ for Cloven et al. [49]. Moore et al. reported 13\% deaths prior to hospital discharge and 30\% within 60 days of surgery [7]. In parallel to these aspects, there is also growing evidence that aging is heterogeneous and that chronological age alone may not be sufficient to predict the ability to withstand operational stress [41]; the worse prognosis for older patients with ovarian cancer probably encompasses both the lack of optimal treatment in fit elderly patients and inadequate surgery in frail ones, with dramatic consequences for subsequent chemotherapy and reduced survival [44].

Taken together, in older patients the treatment decision must therefore consider the risk/benefit ratio of cytoreductive surgery, considering an excess in short-term (perioperative) morbidity and an equivalent benefit over the long term of complete cytoreductive surgery $[5,23]$. The multidisciplinary decision for surgery should include surgical complexity and tumor load, expertise of the surgical team and the technical platform, comprehensive geriatric assessment and patient's motivation towards surgery (importantly including prehabilitation). The purpose of preoperative assessment is to identify patients with an elevated risk of poor outcomes. Current guidelines for preoperative assessment in general [50], but also specifically in older patients [51,52], focus on defining single endorgan functional deficits (i.e., cardiac complications), notably illustrated by the American Heart Association guidelines for perioperative cardiovascular evaluation [50]. Although single organ evaluation cannot be ignored in the older patient population, recognition of preoperative geriatric markers related to frailty may provide additional insight in predicting poor outcomes [53], thus guiding preoperative decision-making. The motivation of the patient towards surgery has to be specifically explored, including a discussion on the risk of postoperative functional decline, loss of independence and skilled care burden, as highlighted by the Best Practices Guidelines on optimal perioperative management of the geriatric patient from the American College of Surgeons NSQIP and the American Geriatrics Society [54]. Pre-surgical assessment should also highlight the personal involvement of the patient in her own care through nutritional and functional prehabilitation as well as the application of enhanced recovery after surgery. The European Society of Gynaecologic Oncology defined in 2016 surgical team quality indicators for advanced ovarian cancer surgery [55]. Among these indicators the first refers to achievement of complete cytoreduction (minimal required target of 50\% and an optimal target of $65 \%$ ), the second to caseload in the center (minimal required target of 20 cases and an optimal target of 100 cases annually) and the third to training and experience of the surgeon (target of more of $90 \%$ of ovarian cancer cytoreductions performed by a trained surgeon specifically dedicated to gynecological cancer management). These recommendations should even be reinforced in the elderly: On the one hand, the expertise of the team has a major impact on the control of postoperative morbidity and the completeness of cytoreduction; on the other hand, elderly patients are more frequently managed by non-oncologists (such as general surgeons and obstetricians/gynecologists [56]) on an emergency basis for cancer complications (occlusion, perforation, infection) and are less likely to undergo surgery in a university hospital [20].

An additional level of complexity in the treatment discussion has come from the OVHIPEC study that found that hyperthermic intraperitoneal chemotherapy (HIPEC) with thiosulfate for nephroprotection improved survival in first-line initially non-resectable ovarian cancer; surgery-related morbidity and mortality at 30 days were comparable in 
the two arms, there was no significant difference in the rate or delay to return to intended adjuvant chemotherapy and there was a positive impact of HIPEC on recurrence-free and overall survival (over a median follow-up of 4.7 years) [57]. Patients included were aged up to 76 years; exploratory analyses on survival found a trend towards a decreased benefit of receiving $\mathrm{HIPEC}$ in those aged $\geq 65$ years $(\mathrm{HR}=0.82,95 \% \mathrm{CI}(0.40-1.68)$ ) compared to younger patients $(\mathrm{HR}=0.60,95 \% \mathrm{CI}(0.34-1.05))$ [57]. In a meta-analysis on cytoreductive surgery and HIPEC regardless of the indication which considered different cut-offs (65, 70,75 years) to analyze the effect of age on patients' outcomes and toxicities, the 70 year threshold appeared to be clinically relevant; the 30-day postoperative grade 3 morbidity and the 90-day postoperative mortality were significantly higher in patients $\geq 70$ years, although this was not associated with a longer hospital stay [58]. In a recent singleinstitution prospective analysis of HIPEC in patients with gynecologic cancers, Chambers et al. found that chronological age ( $<65 \mathrm{vs.} \geq 65$ years) did not predict post-operative complications, progression-free survival or overall survival but that patients aged $\geq 70$ years had a reduced progression-free survival following HIPEC compared to patients 65-69 years without any impact on overall survival [59]. However, the same group later reported that a composite index of 11 medical comorbidities (the modified frailty index, $\mathrm{mFI}$ ) significantly predicted post-operative complications in multivariate analysis, with a more than 9 -fold risk of grade $\geq 2$ complications in those with $\mathrm{mFI} \geq 2$ vs. $0-1$ (OR 9.4, 95\% CI $[3.3 ; 26.4], p<0.001)$, whereas age did not [60].

Cytoreductive surgery with or without HIPEC should, therefore, be decided during a multidisciplinary meeting based on patient motivation, based on a laparoscopic assessment of surgical complexity, the preoperative geriatric and anesthetic assessment and the experience of the team who will perform the surgery. The surgical decisional node (Figure 2) is of major importance considering its expected consequences for short- and long-term morbidity and mortality. Available data on advanced ovarian cancer cytoreductive surgery in older patients are more extensively developed in a future position paper on the surgical agenda of older patients with ovarian cancer endorsed by the SOFOG-GINECO-FRANCOGYN-SFPO.

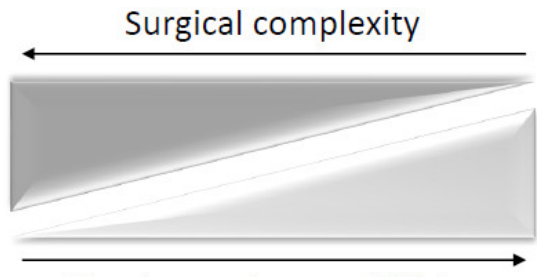

Heaviness of comorbidities

\begin{tabular}{|c|c|}
\hline & Laparoscopic assessment \\
\hline$\omega$ & $\begin{array}{l}\text { - Peritonectomies (including diaphragmatic domes) } \\
\text { - Splenectomy } \\
-1 \text { or } 2 \text { digestive anastomoses }\end{array}$ \\
\hline$F$ & $\begin{array}{l}\text { - Protection ileostomy } \\
\text { - } \text { More than } 2 \text { digestive anastomoses } \\
\text { - Extensive lymphadenectomy (risk of lymphorrhea) }\end{array}$ \\
\hline$\gamma$ & $\begin{array}{l}\text { - Univocal irresectability criteria: } \\
\text { - Mesentery root retraction } \\
\text { - Small intestine serosa miliary } \\
\text { - Invasion of the hepatic pedicle ( } \neq \text { carcinosis of the peritoneum of the pedicle) } \\
\text { - Invasion of the cavo-sus-hepatic confluence (theoretical, satellite of massive carcinomas which } \\
\text { combine other criteria of irresectibility) } \\
\text { - unreasonable surgical procedures } \\
\text { - Total colectomy } \\
\text { - Total / subtotal gastrectomy }\end{array}$ \\
\hline
\end{tabular}

Figure 2. Decision factors to be considered before cytoreductive surgery in older patients with advanced ovarian cancer: the (surgical) green, yellow and red flags.

\section{Adjuvant Treatments: Considering the Place of Targeted Therapies in First Line}

In the setting of cytoreductive surgery with no residue (CCO) surgery, adjuvant treatment and maintenance have been revolutionized by targeted agents. The first was bevacizumab, a VEGF inhibitor that has shown benefit in terms of progression-free survival but not in overall survival in stage-IIIc and IV ovarian cancer [61,62] (Table 1). In the international single-arm ROSiA study on the safety of extending bevacizumab-containing therapy up to 24 months, a post hoc analysis found that grade $\geq 3$ adverse events such as hypertension and thromboembolic events were significantly more frequent in patients aged $\geq 70$ years, but progression-free survival (secondary endpoint) was similar according to this age stratification [63]. The Tolerability of Bevacizumab in Elderly Ovarian Cancer Patients (TURBO) study, which evaluated real-life bevacizumab administration in maintenance, 
found that factors, such as higher creatinine serum levels, eGFR and number of comorbidities, and not age, were associated with bevacizumab-related grade $3 / 4$ toxicity [64]. In this context, bevacizumab should be considered for older patients in the postoperative context taking into account geriatric evaluation considering the absence of overall survival benefit and the risk of adverse events.

Table 1. Randomized studies investigating bevacizumab associated with chemotherapy and maintenance in first-line advanced ovarian cancer-older patient subgroup analyses.

\begin{tabular}{|c|c|c|c|c|c|}
\hline Study & Regimen & Population, $n$ & Older Patients, $n$ & $\begin{array}{l}\text { PFS Population, } \\
\text { Months }\end{array}$ & $\begin{array}{l}\text { Median OS, } \\
\text { Months }\end{array}$ \\
\hline ICON 7r & $\begin{array}{l}\mathrm{CP} \text { vs. } \mathrm{CP}+\mathrm{Bev} \rightarrow \\
\text { Bev maintenance }\end{array}$ & 1528 & Not reported & 17.4 vs. 19.8 & 44.6 vs. 45.5 \\
\hline GOG 218 & $\begin{array}{c}\mathrm{CP}+\text { placebo vs. } \mathrm{CP} \\
+ \text { Bev vs. } \\
\mathrm{CP}+\mathrm{Bev} \rightarrow \mathrm{Bev} \\
\text { maintenance }\end{array}$ & 1873 & $>70$ years: $n=210$ & $\begin{array}{c}10.3 \text { vs. } 11.2 \text { vs. } 14.1 \\
\text { HR } 0.717 \\
p<0.001\end{array}$ & $\begin{array}{c}39.3 \text { vs. } 38.7 \\
\text { vs. } 39.7\end{array}$ \\
\hline
\end{tabular}

Bev: bevacizumab; CP: carboplatin paclitaxel; OS: overall survival; PFS: progression free survival.

A greater improvement came from the availability of PARPi, a novel class anticancer agent targeting homologous recombination [65]. Two different PARPi have been approved for the treatment of first line advanced ovarian cancer, olaparib and niraparib. The study of Olaparib Maintenance Monotherapy in Patients with BRCA Mutated Ovarian Cancer Following First Line Platinum Based Chemotherapy (SOLO1) and Niraparib in Patients with Newly Diagnosed Advanced Ovarian Cancer (PRIMA) studies found a considerable benefit of olaparib and niraparib on tumor control and overall survival, respectively, in BRCAmutated tumors [66,67]; in BRCA wild-type tumors, a significant benefit was also demonstrated with niraparib in the PRIMA study compared to a carboplatin-paclitaxel control arm. In 2019, the PAOLA study found a benefit of the olaparib and bevacizumab combined maintenance over bevacizumab only in BRCA-mutated and homologous recombinationdeficient (HRD) tumors; there was no benefit in the homologous recombination-proficient tumors [2]. This novel therapeutic option leads to a greater individualization of patient treatment, but at the same time increases the complexity of treatment decisions as more information is required to be collected; each patient-even at older ages-should be proposed somatic/germinal analysis of the tumor, seeking BRCA 1 and 2 mutation, but also $\mathrm{HRD} / \mathrm{P}$ score. An oncogenetic consultation is also recommended for patients over 70 with a family history.

The Young International Society of Geriatric Oncology (SIOG) Interest Group reviewed in 2019 the data available in clinical trials on age-specific tolerance of olaparib (eight phase $1 / 2$ trials) and niraparib; if no difference in toxicity was shown between $<65$ and $\geq 65$ [68], the authors highlighted that only a very small proportion of the patients were $>75$, none were $>85$ and almost all had an ECOG performance status of 0 or 1 [69]. A subsequent subgroup analysis of the Maintenance Study with Niraparib Versus Placebo in Patients With Platinum Sensitive Ovarian Cancer (NOVA) trial in patients aged $\geq 70$ years with recurrent ovarian cancer found that older patients benefited from niraparib with comparable frequency, severity of adverse events $(34.4 \%, 13.1 \%$ and $16.4 \%$ grade $\geq 3$ thrombopenia, anemia and neutropenia events, respectively), and dose reductions [14] (Table 2). 
Table 2. Randomized studies on PARPi maintenance in first-line advanced ovarian cancer-older patient subgroup analyses.

\begin{tabular}{|c|c|c|c|c|}
\hline Study & Population, $n$ & Older Patients, $n$ & $\begin{array}{l}\text { Hazard Ratio (HR) for Disease } \\
\text { Progression or Death }\end{array}$ & $\begin{array}{l}\text { Grade 3-4 Adverse Events in } \\
\text { Older Patients If Known }\end{array}$ \\
\hline SOLO1 & 391 & $\geq 65: 68$ & $\begin{array}{c}\text { HR } 0.45 \\
95 \% \text { CI }(0.22-0.92)\end{array}$ & $\begin{array}{c}\text { Anemia general population } \\
22 \% \\
\text { Neutropenia } 9 \%\end{array}$ \\
\hline PRIMA & 733 & $\geq 65: 219$ & $\begin{array}{c}\text { HR } 0.53 \\
95 \% \text { CI }(0.38-0.74)\end{array}$ & $\begin{array}{c}\text { Anemia } 31 \% \\
\text { Thrombopenia } 28.7 \%\end{array}$ \\
\hline NOVA & $311+61$ & $\geq 70: 61$ & $\begin{array}{c}\text { BRCAm: } \\
\text { HR 0.09 } \\
\text { (95\% CI: 0.01-0.73) } \\
\text { PFS: not reached vs. 3.7 months } \\
\text { BRCAw: } \\
\text { HR 0.35 } \\
\text { 95\% CI }(0.18-0.71) \\
\text { PFS: } 11.3 \text { months vs. } 3.8 \text { months }\end{array}$ & $\begin{array}{c}\text { Thrombopenia } 34.4 \% \\
\text { Neutropenia } 16.4 \% \\
\text { Fatigue } 8.2 \%\end{array}$ \\
\hline
\end{tabular}

BRCAm: BRCA mutated; BRCAw: BRCA wild type; PFS: progression free survival.

Although chronologic age itself does not seem to significantly increase toxicities in response to PARPi (no preventive dose adjustment is necessary for older patients), specific attention must be paid to the high prevalence of chronic fatigue with a major impact in an older population [69] and to the risks of increased exposure to the treatment in case of comorbidities or polypharmacy due to drug-drug interactions and renal or hepatic impairment [70]. Differences in toxicity profiles of the drugs could be related to their pharmacokinetics. As with many oral targeted therapies, association has been shown between drug exposure and increasing probability of experiencing adverse effects. The exposure to olaparib is indeed increased in case of moderate renal impairment (dose adjustment) [71]; the area-under-the curve of niraparib depends on age, creatinine clearance, weight, albuminemia [72] and increases in case of moderate hepatic impairment (leading to a recommended starting dose of $200 \mathrm{mg}$ ) [73]. Niraparib tolerance was shown to be optimized with an individualized starting dose of 200 instead of $300 \mathrm{mg}$ in case of persistent thrombopenia after chemotherapy $<150,000 / \mu \mathrm{L}$ and / or bodyweight $<77 \mathrm{~kg}$ whatever the patient's age $[74,75]$. Considering their metabolism, olaparib and niraparib have substantial differences: olaparib is mainly metabolized by cytochrome (CYP) $3 \mathrm{~A} 4 / 5$ enzymes; is a substrate of P-glycoprotein (P-gp); induces in vitro CYP1A2, 2B6 and 3A4 and inhibits in vitro CYP3A, P-gp, BCRP, OATP1B1, OCT1, OCT2, OAT3, MATE1 and MATE2K. Niraparib is mainly metabolized by carboxylesterases; it is a substrate of P-gp and BCRP and inhibits MATE1/2 and OCT1 [70]. In a multidisciplinary context, pharmaceutical consultation may be implemented to secure and optimize PARPi treatment and associated supportive care, especially in older population. The high risk of drug-drug interactions should offer the opportunity, in the older population, to a pharmaceutical optimization step with a complete comprehensive medication review including non-prescription and complementary (herbal) medications [76]. Patient education represents a significant proportion of treatment success [77], and a clear treatment plan needs to be established in the relationship between the patient and her caregivers with explanation of side effects and prevention and adaptation of the treatment plan to the vulnerabilities identified during the geriatric assessment. After prolonged exposure, PARPi-treated patients were shown to have an increased risk of myelodysplastic syndromes (OR 2.63 [95\% CI 1.13-6.14], $p=0.026$ ) [78]. Future phase IV studies will be of interest to evaluate whether, as expected, this risk is increased at older ages. Patients should be clearly informed, and the hematological biological monitoring should be performed carefully. 
Studies are currently ongoing with immunotherapy alone or in combination with bevacizumab and PARPi. The results, if positive, could again lead to change the strategy in the first line setting.

\section{Conclusions}

Multi-disciplinarity, anticipation and patient motivation are the key rules during care planning of ovarian cancer in older patients. Each step of the treatment plan should be reconsidered in the light of a geriatric assessment and follow-up. Specific studies remain sparse and should be encouraged in the future to evaluate the impact of geriatric vulnerability parameters at each step of the treatment agenda and the impact of geriatric interventions on patients' outcomes.

Author Contributions: Conceptualization, C.F.; methodology, L.B., N.B., F.R., V.L. and C.F.; software, not applicable (na); validation, L.B., N.B., F.R., V.L. and C.F.; formal analysis, na; investigation, L.B., N.B., F.R., V.L. and C.F.; resources, L.B., N.B., F.R., V.L. and C.F.; data curation, L.B., N.B., F.R., V.L. and C.F.; writing (original draft preparation, review and editing), L.B., N.B., F.R., V.L. and C.F.; visualization, L.B., N.B., F.R., V.L. and C.F.; supervision, C.F.; project administration, C.F.; funding acquisition, na. All authors have read and agreed to the published version of the manuscript.

Funding: This research received no external funding.

Informed Consent Statement: Not applicable.

Data Availability Statement: Not applicable.

Acknowledgments: The authors thank Christophe Bardin (SFPO), Nicolas Bertrand (SOFOG), AnneLaure Couderc (SOFOG), Cyrille Huchon (FRANCOGYN) Florence Joly (GINECO), Jean-Emmanuel Kurtz (GINECO), Lobna Ouldamer (FRANCOGYN), Emilie Petit-Jean (SFPO), Florence Ranchon (SFPO), Cyril Touboul (FRANCOGYN) and Pascale Jubelin from the IMAGYN association (initiative of patients treated for gynecological cancers) for reviewing this position paper and Philip Robinson for his help in manuscript writing.

Conflicts of Interest: L.B. reported personal fees from AstraZeneca, Clovis Oncology and GlaxoSmithKline. F.R. reported participation in a specialist advisory board for Bristol-Myers Squibb. C.F. reported personal fees from Leo Pharma, Pfizer, MSD Oncology, Teva, AstraZeneca, Baxter, Eisai, Janssen Oncology, Novartis, Chugai Pharma and Astellas Pharma outside the submitted work; grants from Chugai Pharma, Pfizer, Pierre Fabre and Astellas Pharma outside the submitted work and non-financial support from Janssen Oncology, Pierre Fabre, AstraZeneca and Leo Pharma outside the submitted work. N.B. and V.L. declared no conflict of interest.

\section{References}

1. Gockley, A.; Melamed, A.; Bregar, A.J.; Clemmer, J.T.; Birrer, M.; Schorge, J.O.; Del Carmen, M.G.; Rauh-Hain, J.A. Outcomes of Women With High-Grade and Low-Grade Advanced-Stage Serous Epithelial Ovarian Cancer. Obstet. Gynecol. 2017, 129, 439-447. [CrossRef]

2. Ray-Coquard, I.; Pautier, P.; Pignata, S.; Pérol, D.; González-Martín, A.; Berger, R.; Fujiwara, K.; Vergote, I.; Colombo, N.; Mäenpää, J.; et al. Olaparib plus Bevacizumab as First-Line Maintenance in Ovarian Cancer. N. Engl. J. Med. 2019, 381, 2416-2428. [CrossRef] [PubMed]

3. Dion, L.; Mimoun, C.; Timoh, K.N.; Bendifallah, S.; Bricou, A.; Collinet, P.; Touboul, C.; Ouldamer, L.; Azaïs, H.; Dabi, Y.; et al. Ovarian Cancer in the Elderly: Time to Move towards a More Logical Approach to Improve Prognosis-A Study from the FRANCOGYN Group. J. Clin. Med. 2020, 9, 1339. [CrossRef] [PubMed]

4. Schuurman, M.; Kruitwagen, R.; Portielje, J.; Roes, E.; Lemmens, V.; van der Aa, M. Treatment and outcome of elderly patients with advanced stage ovarian cancer: A nationwide analysis. Gynecol. Oncol. 2018, 149, 270-274. [CrossRef] [PubMed]

5. Jørgensen, T.L.; Teiblum, S.; Paludan, M.; Poulsen, L.; Jørgensen, A.Y.S.; Bruun, K.H.; Hallas, J.; Herrstedt, J. Significance of age and comorbidity on treatment modality, treatment adherence, and prognosis in elderly ovarian cancer patients. Gynecol. Oncol. 2012, 127, 367-374. [CrossRef]

6. Lavoue, V.; Huchon, C.; Akladios, C.; Alfonsi, P.; Bakrin, N.; Ballester, M.; Bendifallah, S.; Bolze, P.; Bonnet, F.; Bourgin, C.; et al. Management of epithelial cancer of the ovary, fallopian tube, primary peritoneum. Long text of the joint French clinical practice guidelines issued by FRANCOGYN, CNGOF, SFOG, GINECO-ARCAGY, endorsed by INCa. (Part 2: Systemic, intraperitoneal treatment, elderly patients, fertility preservation, follow-up). J. Gynecol. Obstet. Hum. Reprod. 2019, 48, 379-386. [CrossRef] 
7. Moore, K.N.; Reid, M.S.; Fong, D.N.; Myers, T.K.; Landrum, L.M.; Moxley, K.M.; Walker, J.L.; McMeekin, D.S.; Mannel, R.S. Ovarian Cancer in the Octogenarian: Does the Paradigm of Aggressive Cytoreductive Surgery and Chemotherapy Still Apply? Gynecol. Oncol. 2008, 110, 133-139. [CrossRef]

8. Talarico, L.; Chen, G.; Pazdur, R. Enrollment of Elderly Patients in Clinical Trials for Cancer Drug Registration: A 7-Year Experience by the US Food and Drug Administration. J. Clin. Oncol. 2004, 22, 4626-4631. [CrossRef]

9. Harter, P.; Du Bois, A.; Schade-Brittinger, C.; Burges, A.; Wollschlaeger, K.; Gropp, M.; Schmalfeldt, B.; Huober, J.; Staehle, A.; Pfisterer, J. Non-enrolment of ovarian cancer patients in clinical trials: Reasons and background. Ann. Oncol. 2005, 16, 1801-1805. [CrossRef]

10. Townsley, C.A.; Selby, R.; Siu, L.L. Systematic Review of Barriers to the Recruitment of Older Patients With Cancer Onto Clinical Trials. J. Clin. Oncol. 2005, 23, 3112-3124. [CrossRef]

11. Villella, J.; Chalas, E. Optimising Treatment of Elderly Patients with Ovarian Cancer: Improving Their En-rollment in Clinical Trials. Drugs Aging 2005, 22, 95-100. [CrossRef] [PubMed]

12. Eisenhauer, E.L.; Tew, W.P.; Levine, D.A.; Lichtman, S.M.; Brown, C.L.; Aghajanian, C.; Huh, J.; Barakat, R.R.; Chi, D.S. Response and Outcomes in Elderly Patients with Stages IIIC-IV Ovarian Cancer Receiving Plati-num-Taxane Chemotherapy. Gynecol. Oncol. 2007, 106, 381-387. [CrossRef]

13. Hilpert, F.; du Bois, A.; Greimel, E.; Hedderich, J.; Krause, G.; Venhoff, L.; Loibl, S.; Pfisterer, J. Feasibility, toxicity and quality of life of first-line chemotherapy with platinum/paclitaxel in elderly patients aged $\geq 70$ years with advanced ovarian cancer-A study by the AGO OVAR Germany. Ann. Oncol. 2007, 18, 282-287. [CrossRef] [PubMed]

14. Fabbro, M.; Moore, K.N.; Dørum, A.; Tinker, A.V.; Mahner, S.; Bover, I.; Banerjee, S.; Tognon, G.; Goffin, F.; Shapira-Frommer R.; et al. Efficacy and safety of niraparib as maintenance treatment in older patients ( $\geq 70$ years) with recurrent ovarian cancer: Results from the ENGOT-OV16/NOVA trial. Gynecol. Oncol. 2019, 152, 560-567. [CrossRef]

15. Defossez, G.; Uhry, Z.; Delafosse, P.; Dantony, E.; D'Almeida, T.; Plouvier, S.; Bossard, N.; Bouvier, A.M.; Molinié, F.; Woronoff, A.S.; et al. Cancer incidence and mortality trends in France over 1990-2018 for solid tumors: The sex gap is narrowing. BMC Cancer 2021, 21, 1-14. [CrossRef] [PubMed]

16. Freyer, G.; Tinker, A.V. Clinical Trials and Treatment of the Elderly Diagnosed With Ovarian Cancer. Int. J. Gynecol. Cancer 2011, 21, 776-781. [CrossRef]

17. Lavoue, V.; Huchon, C.; Akladios, C.; Alfonsi, P.; Bakrin, N.; Ballester, M.; Bendifallah, S.; Bolze, P.; Bonnet, F.; Bourgin, C.; et al Management of epithelial cancer of the ovary, fallopian tube, and primary peritoneum. Short text of the French Clinical Practice Guidelines issued by FRANCOGYN, CNGOF, SFOG, and GINECO-ARCAGY, and endorsed by INCa. Eur. J. Obstet. Gynecol. Reprod. Biol. 2019, 236, 214-223. [CrossRef]

18. Heppenstall, C.P.; Wilkinson, T.J.; Hanger, H.C.; Keeling, S. Frailty: Dominos or Deliberation? N. Z. Med. J. $2009,122,42-53$.

19. Petignat, P.; Fioretta, G.; Verkooijen, H.; Vlastos, A.; Rapiti, E.; Bouchardy, C.; Vlastos, G. Poorer survival of elderly patients with ovarian cancer: A population-based study. Surg. Oncol. 2004, 13, 181-186. [CrossRef]

20. Díaz-Montes, T.P.; Zahurak, M.L.; Giuntoli, R.L.; Gardner, G.J.; Gordon, T.A.; Armstrong, D.K.; Bristow, R.E. Surgical care of elderly women with ovarian cancer: A population-based perspective. Gynecol. Oncol. 2005, 99, 352-357. [CrossRef]

21. Falandry, C.; Weber, B.; Savoye, A.-M.; Tinquaut, F.; Tredan, O.; Sevin, E.; Stefani, L.; Savinelli, F.; Atlassi, M.; Salvat, J.; et al Development of a geriatric vulnerability score in elderly patients with advanced ovarian cancer treated with first-line carboplatin: A GINECO prospective trial. Ann. Oncol. 2013, 24, 2808-2813. [CrossRef] [PubMed]

22. Dhakal, P.; Wichman, C.S.; Pozehl, B.; Weaver, M.; Fisher, A.L.; Vose, J.; Bociek, R.G.; Bhatt, V.R. Preferences of adults with cancer for systemic cancer treatment: Do preferences differ based on age? Futur. Oncol. 2022, 18, 311-321. [CrossRef] [PubMed]

23. Bristow, R.E.; Tomacruz, R.S.; Armstrong, D.K.; Trimble, E.L.; Montz, F.J. Survival Effect of Maximal Cytore-ductive Surgery for Advanced Ovarian Carcinoma during the Platinum Era: A Meta-Analysis. J. Clin. Oncol. 2002, 20, 1248-1259. [CrossRef] [PubMed]

24. Tan, H.-J.; Saliba, D.; Kwan, L.; Moore, A.A.; Litwin, M. Burden of Geriatric Events Among Older Adults Undergoing Major Cancer Surgery. J. Clin. Oncol. 2016, 34, 1231-1238. [CrossRef]

25. Bruchim, I.; Altaras, M.; Fishman, A. Age Contrasts in Clinical Characteristics and Pattern of Care in Patients with Epithelial Ovarian Cancer. Gynecol. Oncol. 2002, 86, 274-278. [CrossRef]

26. Classe, J.-M.; Guyon, F.; Falandry, C.; Devouassoux-Shisheboran, M.; Selle, F.; Joly, F. Cancer de l'ovaire: Prise en charge pluridisciplinaire du cancer de l'ovaire en première ligne: Recommandations Saint-Paul-de-Vence 2016. Bull. du Cancer 2017, 104, S6-S15. [CrossRef]

27. Thrall, M.M.; Goff, B.A.; Symons, R.G.; Flum, D.R.; Gray, H.J. Thirty-Day Mortality after Primary Cytoreduc-tive Surgery for Advanced Ovarian Cancer in the Elderly. Obstet. Gynecol. 2011, 118, 537-547. [CrossRef]

28. Poonawalla, I.B.; Lairson, D.R.; Chan, W.; Piller, L.B.; Du, X.L. Cost-Effectiveness of Neoadjuvant Chemotherapy versus Primary Surgery in Elderly Patients with Advanced Ovarian Cancer. Value Health 2015, 18, 387-395. [CrossRef]

29. van Meurs, H.S.; Tajik, P.; Hof, M.H.; Vergote, I.; Kenter, G.G.; Mol, B.W.; Buist, M.R.; Bossuyt, P.M. Which Pa-tients Benefit Most from Primary Surgery or Neoadjuvant Chemotherapy in Stage IIIC or IV Ovarian Cancer? An Exploratory Analysis of the European Organisation for Research and Treatment of Cancer 55971 Randomised Trial. Eur. J. Cancer 2013, 49, 3191-3201. [CrossRef] 
30. McCluggage, W.G.; Young, R.H. Immunohistochemistry as a diagnostic aid in the evaluation of ovarian tumors. Semin. Diagn. Pathol. 2005, 22, 3-32. [CrossRef]

31. Yedema, C.; Kenemans, P.; Wobbes, T.; Thomas, C.; Bon, G.; Mulder, C.; Voorhorst, F.; Verstraeten, A.; Van Kamp, G.; Hilgers, J. Use of Serum Tumor Markers in the Differential Diagnosis between Ovarian and Colorectal Adenocarcinomas. Tumor Biol. 1992, 13, 18-26. [CrossRef] [PubMed]

32. Vergote, I.; du Bois, A.; Amant, F.; Heitz, F.; Leunen, K.; Harter, P. Neoadjuvant Chemotherapy in Advanced Ovarian Cancer: On What Do We Agree and Disagree? Gynecol. Oncol. 2013, 128, 6-11. [CrossRef] [PubMed]

33. Ataseven, B.; du Bois, A.; Reinthaller, A.; Traut, A.; Heitz, F.; Aust, S.; Prader, S.; Polterauer, S.; Harter, P.; Grimm, C. Pre-operative serum albumin is associated with post-operative complication rate and overall survival in patients with epithelial ovarian cancer undergoing cytoreductive surgery. Gynecol. Oncol. 2015, 138, 560-565. [CrossRef] [PubMed]

34. Freyer, G.; Geay, J.-F.; Touzet, S.; Provencal, J.; Weber, B.; Jacquin, J.-P.; Ganem, G.; Tubiana-Mathieu, N.; Gisserot, O.; PujadeLauraine, E. Comprehensive geriatric assessment predicts tolerance to chemotherapy and survival in elderly patients with advanced ovarian carcinoma: A GINECO study. Ann. Oncol. 2005, 16, 1795-1800. [CrossRef]

35. Tredan, O.; Geay, J.-F.; Touzet, S.; Delva, R.; Weber, B.; Cretin, J.; Provencal, J.; Martin, J.; Stefani, L.; Pujade-Lauraine, E.; et al. Carboplatin/cyclophosphamide or carboplatin/paclitaxel in elderly patients with advanced ovarian cancer? Analysis of two consecutive trials from the Groupe d'Investigateurs Nationaux pour l'Etude des Cancers Ovariens. Ann. Oncol. 2007, 18, 256-262. [CrossRef]

36. Pignata, S.; Breda, E.; Scambia, G.; Pisano, C.; Zagonel, V.; Lorusso, D.; Greggi, S.; De Vivo, R.; Ferrandina, M.G.; Gallo, C.; et al. A phase II study of weekly carboplatin and paclitaxel as first-line treatment of elderly patients with advanced ovarian cancer: A Multicentre Italian Trial in Ovarian cancer (MITO-5) study. Crit. Rev. Oncol. 2008, 66, 229-236. [CrossRef]

37. Falandry, C.; Rousseau, F.; Mouret-Reynier, M.-A.; Tinquaut, F.; Lorusso, D.; Herrstedt, J.; Savoye, A.-M.; Stefani, L.; Bourbouloux, E.; Sverdlin, R.; et al. Efficacy and Safety of First-line Single-Agent Carboplatin vs Carboplatin Plus Paclitaxel for Vulnerable Older Adult Women With Ovarian Cancer. JAMA Oncol. 2021, 7, 853. [CrossRef]

38. Nightingale, G.; Battisti, N.M.L.; Loh, K.P.; Puts, M.; Kenis, C.; Goldberg, A.; Haase, K.R.; Krok-Schoen, J.; Liposits, G.; Sattar, S.; et al. Perspectives on functional status in older adults with cancer: An interprofessional report from the International Society of Geriatric Oncology (SIOG) nursing and allied health interest group and young SIOG. J. Geriatr. Oncol. 2020, 12, 658-665. [CrossRef]

39. Puts, M.; Strohschein, F.; Oldenmenger, W.; Haase, K.; Newton, L.; Fitch, M.; Sattar, S.; Stolz-Baskett, P.; Jin, R.; Loucks, A.; et al. Position statement on oncology and cancer nursing care for older adults with cancer and their caregivers of the International Society of Geriatric Oncology Nursing and Allied Health Interest Group, the Canadian Association of Nurses in Oncology Oncology \& Aging Special Interest Group, and the European Oncology Nursing Society. J. Geriatr. Oncol. 2021, 12, 1000-1004. [CrossRef]

40. Hoppenot, C.; Eckert, M.; Tienda, S.M.; Lengyel, E. Who are the long-term survivors of high grade serous ovarian cancer? Gynecol. Oncol. 2018, 148, 204-212. [CrossRef]

41. Poupon, C.; Bendifallah, S.; Ouldamer, L.; Canlorbe, G.; Raimond, E.; Hudry, N.; Coutant, C.; Graesslin, O.; Touboul, C.; Collinet, P.; et al. Management and Survival of Elderly and Very Elderly Patients with Endometrial Cancer: An Age-Stratified Study of 1228 Women from the FRANCOGYN Group. Ann. Surg. Oncol. 2016, 24, 1667-1676. [CrossRef] [PubMed]

42. Chéreau, E.; Ballester, M.; Selle, F.; Rouzier, R.; Daraï, E. Ovarian cancer in the elderly: Impact of surgery on morbidity and survival. Eur. J. Surg. Oncol. (EJSO) 2011, 37, 537-542. [CrossRef] [PubMed]

43. Thigpen, T.; Brady, M.F.; Omura, G.A.; Creasman, W.T.; McGuire, W.P.; Hoskins, W.J.; Williams, S. Age as a prognostic factor in ovarian carcinoma: The gynecologic oncology group experience. Cancer 2010, 71, 606-614. [CrossRef] [PubMed]

44. Wright, J.D.; Herzog, T.J.; Neugut, A.I.; Burke, W.M.; Lu, Y.-S.; Lewin, S.N.; Hershman, D.L. Effect of Radical Cytoreductive Surgery on Omission and Delay of Chemotherapy for Advanced-Stage Ovarian Cancer. Obstet. Gynecol. 2012, 120, 871-881. [CrossRef] [PubMed]

45. Wright, J.D.; Herzog, T.J.; Powell, M.A. Morbidity of Cytoreductive Surgery in the Elderly. Am. J. Obstet. Gynecol. 2004, 190, 1398-1400. [CrossRef]

46. Wright, J.D.; Lewin, S.N.; Deutsch, I.; Burke, W.M.; Sun, X.; Neugut, A.I.; Herzog, T.J.; Hershman, D.L. Defin-ing the Limits of Radical Cytoreductive Surgery for Ovarian Cancer. Gynecol. Oncol. 2011, 123, 467-473. [CrossRef]

47. Gerestein, C.; Boer, G.N.-D.; Eijkemans, M.; Kooi, G.; Burger, C. Prediction of 30-day morbidity after primary cytoreductive surgery for advanced stage ovarian cancer. Eur. J. Cancer 2010, 46, 102-109. [CrossRef]

48. Gerestein, C.G.; Damhuis, R.A.; Burger, C.W.; Kooi, G.S. Postoperative mortality after primary cytoreductive surgery for advanced stage epithelial ovarian cancer: A systematic review. Gynecol. Oncol. 2009, 114, 523-527. [CrossRef]

49. Cloven, N.G.; Manetta, A.; Berman, M.L.; Kohler, M.F.; DiSaia, P.J. Management of Ovarian Cancer in Patients Older Than 80 Years of Age. Gynecol. Oncol. 1999, 73, 137-139. [CrossRef]

50. Fleisher, L.A.; Beckman, J.; Brown, K.A.; Calkins, H.; Chaikof, E.L.; Fleischmann, K.E.; Freeman, W.K.; Froehlich, J.B.; Kasper, E.K.; Kersten, J.R.; et al. ACC/AHA 2007 Guidelines on Perioperative Cardiovascular Evaluation and Care for Noncardiac Surgery. Circulation 2007, 116, e418-e500. [CrossRef]

51. Richardson, J.D.; Cocanour, C.S.; Kern, J.A.; Garrison, R.N.; Kirton, O.C.; Cofer, J.B.; Spain, D.A.; Thomason, M.H. Perioperative risk assessment in elderly and high-risk patients. J. Am. Coll. Surg. 2004, 199, 133-146. [CrossRef] [PubMed] 
52. Jin, F.; Chung, F. Minimizing perioperative adverse events in the elderly. Br. J. Anaesth. 2001, 87, 608-624. [CrossRef] [PubMed]

53. Dasgupta, M.; Rolfson, D.B.; Stolee, P.; Borrie, M.J.; Speechley, M. Frailty is associated with postoperative complications in older adults with medical problems. Arch. Gerontol. Geriatr. 2009, 48, 78-83. [CrossRef]

54. Mohanty, S.; Rosenthal, R.A.; Russell, M.M.; Neuman, M.D.; Ko, C.Y.; Esnaola, N.F. Optimal Perioperative Management of the Geriatric Patient: A Best Practices Guideline from the American College of Surgeons NSQIP and the American Geriatrics Society. J. Am. Coll. Surg. 2016, 222, 930-947. [CrossRef] [PubMed]

55. Querleu, D.; Planchamp, F.; Chiva, L.; Fotopoulou, C.; Barton, D.; Cibula, D.; Aletti, G.; Carinelli, S.; Creutzberg, C.; Davidson, B.; et al. European Society of Gynaecologic Oncology Quality Indicators for Advanced Ovarian Cancer Surgery. Int. J. Gynecol. Cancer 2016, 26, 1354-1363. [CrossRef] [PubMed]

56. Hightower, R.D.; Nguyen, H.N.; Averette, H.E.; Hoskins, W.; Harrison, T.; Steren, A. National survey of ovarian carcinoma IV: Patterns of care and related survival for older patients. Cancer 1994, 73, 377-383. [CrossRef]

57. Ceresoli, M.; Frigerio, L.; Ansaloni, L. Hyperthermic Intraperitoneal Chemotherapy in Ovarian Cancer. N. Engl. J. Med. 2018, 378, 1362-1364. [CrossRef]

58. Gagnière, J. HIPEC in the Elderly: A Meta-Analysis. Ann. Surg. Oncol. 2018, 25, 701-702. [CrossRef]

59. Chambers, L.M.; Yao, M.; Morton, M.; Chichura, A.; Costales, A.B.; Horowitz, M.; Gruner, M.F.; Rose, P.G.; Michener, C.M.; DeBernardo, R. Perioperative outcomes of cytoreductive surgery with hyperthermic intraperitoneal chemotherapy in elderly women with epithelial ovarian cancer: Analysis of a prospective registry. Int. J. Gynecol. Cancer 2021, 31, 1021-1030. [CrossRef]

60. Chambers, L.M.; Chalif, J.; Yao, M.; Chichura, A.; Morton, M.; Gruner, M.; Costales, A.B.; Horowitz, M.; Chau, D.B.; Vargas, R.; et al. Modified frailty index predicts postoperative complications in women with gynecologic cancer undergoing cytoreductive surgery and hyperthermic intraperitoneal chemotherapy. Gynecol. Oncol. 2021, 162, 368-374. [CrossRef]

61. Burger, R.A.; Brady, M.F.; Bookman, M.A.; Fleming, G.F.; Monk, B.J.; Huang, H.; Mannel, R.S.; Homesley, H.D.; Fowler, J.; Greer, B.E.; et al. Incorporation of Bevacizumab in the Primary Treatment of Ovarian Cancer. N. Engl. J. Med. 2011, 365, $2473-2483$. [CrossRef] [PubMed]

62. Perren, T.J.; Swart, A.M.; Pfisterer, J.; Ledermann, J.A.; Pujade-Lauraine, E.; Kristensen, G.; Carey, M.S.; Beale, P.; Cervantes, A.; Kurzeder, C.; et al. A Phase 3 Trial of Bevacizumab in Ovarian Cancer. N. Engl. J. Med. 2011, 365, 2484-2496. [CrossRef] [PubMed]

63. Selle, F.; Colombo, N.; Korach, J.; Mendiola, C.; Cardona, A.; Ghazi, Y.; Oza, A. Safety and Efficacy of Extended Bevacizumab Therapy in Elderly ( $\geq 70$ Years) Versus Younger Patients Treated for Newly Diagnosed Ovarian Cancer in the International ROSiA Study. Int. J. Gynecol. Cancer 2018, 28, 729-737. [CrossRef] [PubMed]

64. Amadio, G.; Marchetti, C.; Villani, E.R.; Fusco, D.; Stollagli, F.; Bottoni, C.; Di Stefano, M.; Colloca, G.; Scambia, G.; Fagotti, A. ToleRability of BevacizUmab in elderly Ovarian cancer patients (TURBO study): A case-control study of a real-life experience. J. Gynecol. Oncol. 2020, 31. [CrossRef] [PubMed]

65. Liu, F.W.; Tewari, K.S. New Targeted Agents in Gynecologic Cancers: Synthetic Lethality, Homologous Recombination Deficiency, and PARP Inhibitors. Curr. Treat. Options Oncol. 2016, 17, 1-15. [CrossRef]

66. Moore, K.; Colombo, N.; Scambia, G.; Kim, B.-G.; Oaknin, A.; Friedlander, M.; Lisyanskaya, A.; Floquet, A.; Leary, A.; Sonke, G.S.; et al. Maintenance Olaparib in Patients with Newly Diagnosed Advanced Ovarian Cancer. N. Engl. J. Med. 2018, 379, $2495-2505$. [CrossRef]

67. González-Martín, A.; Pothuri, B.; Vergote, I.; DePont Christensen, R.; Graybill, W.; Mirza, M.R.; McCormick, C.; Lorusso, D.; Hoskins, P.; Freyer, G.; et al. Niraparib in Patients with Newly Diagnosed Advanced Ovarian Cancer. N. Engl. J. Med. 2019, 381, 2391-2402. [CrossRef]

68. Dockery, L.E.; Tew, W.P.; Ding, K.; Moore, K.N. Tolerance and toxicity of the PARP inhibitor olaparib in older women with epithelial ovarian cancer. Gynecol. Oncol. 2017, 147, 509-513. [CrossRef]

69. Liposits, G.; Loh, K.P.; Soto-Perez-De-Celis, E.; Dumas, L.; Battisti, N.M.L.; Kadambi, S.; Baldini, C.; Banerjee, S.; Lichtman, S.M. PARP inhibitors in older patients with ovarian and breast cancer: Young International Society of Geriatric Oncology review paper. J. Geriatr. Oncol. 2018, 10, 337-345. [CrossRef]

70. Valabrega, G.; Scotto, G.; Tuninetti, V.; Pani, A.; Scaglione, F. Differences in PARP Inhibitors for the Treatment of Ovarian Cancer: Mechanisms of Action, Pharmacology, Safety, and Efficacy. Int. J. Mol. Sci. 2021, 22, 4203. [CrossRef]

71. Reddy, V.P.; Bui, K.; Scarfe, G.; Zhou, D.; Learoyd, M. Physiologically Based Pharmacokinetic Modeling for Olaparib Dosing Recommendations: Bridging Formulations, Drug Interactions, and Patient Populations. Clin. Pharmacol. Ther. 2018, 105, $229-241$. [CrossRef] [PubMed]

72. Monk, B.J.; Romero, I.; Graybill, W.; Churruca, C.; O’Malley, D.M.; Lund, B.; Yap, O.W.S.; Baurain, J.-F.; Rose, P.G.; Denys, H.; et al. Niraparib exposure-response relationship in patients (pts) with newly diagnosed advanced ovarian cancer (AOC). J. Clin. Oncol. 2020, 38, 6051. [CrossRef]

73. Akce, M.; El-Khoueiry, A.; Piha-Paul, S.A.; Bacque, E.; Pan, P.; Zhang, Z.-Y.; Ewesuedo, R.; Gupta, D.; Tang, Y.; Milton, A.; et al. Pharmacokinetics and safety of niraparib in patients with moderate hepatic impairment. Cancer Chemother. Pharmacol. 2021, 88, 825-836. [CrossRef] [PubMed]

74. Mirza, M.R.; Martin, A.G.; Graybill, W.; O’Malley, D.M.; Gaba, L.; Yap, O.W.S.; Guerra, E.M.; Rose, P.G.; Baurain, J.-F.; Ghamande, S.A.; et al. Evaluation of an individualized starting-dose of niraparib in the PRIMA/ENGOT-OV26/GOG-3012 study. J. Clin. Oncol. 2020, 38, 6050. [CrossRef] 
75. Valabrega, G.; Pothuri, B.; Oaknin, A.; Graybill, W.; Sánchez, A.; Mccormick, C.; Baurain, J.-F.; Hoskins, P.; Denys, H.; O’Cearbhaill, R.; et al. 819P Efficacy and safety of niraparib in older patients (pts) with advanced ovarian cancer (OC): Results from the PRIMA/ENGOT-OV26/GOG-3012 trial. Ann. Oncol. 2020, 31, S619. [CrossRef]

76. Nightingale, G.; Hajjar, E.; Pizzi, L.T.; Wang, M.; Pigott, E.; Doherty, S.; Prioli, K.; Swartz, K.; Chapman, A.E. Implementing a pharmacist-led, individualized medication assessment and planning (iMAP) intervention to reduce medication related problems among older adults with cancer. J. Geriatr. Oncol. 2017, 8, 296-302. [CrossRef]

77. Ruddy, K.; Mayer, E.; Partridge, A. Patient adherence and persistence with oral anticancer treatment. CA Cancer J. Clin. 2009, 59, 56-66. [CrossRef]

78. Morice, P.-M.; Leary, A.; Dolladille, C.; Chrétien, B.; Poulain, L.; González-Martín, A.; Moore, K.; O’Reilly, E.M.; Ray-Coquard, I.; Alexandre, J. Myelodysplastic syndrome and acute myeloid leukaemia in patients treated with PARP inhibitors: A safety meta-analysis of randomised controlled trials and a retrospective study of the WHO pharmacovigilance database. Lancet Haematol. 2020, 8, e122-e134. [CrossRef] 